\title{
Keratoacanthoma in an acrochordon
} Akrokordon içinde keratoakantom

Keywords: Acrochordon, fibroepithelial polyp, histopathology, keratoacanthoma, skin tag

Anahtar Kelimeler: Akrokordon, fibroepitelyal polip, histopatoloji, keratoakantom, yumuşak fibrom

To the editor,

Acrochorda are common skin outgrowths. They are pedunculated connective tissue tumors that can be $1 \mathrm{~mm}$ to several centimeters in dimension.

A 33-year-old woman applied to the dermatology outpatient clinic with a fast growing lesion in the neck for three months following local trauma. The mass first developed during pregnancy eight years ago. A $6 \mathrm{~mm}$ sized, pedinculated, round lesion was present in the left side of the neck on dermatological examination (Figure 1). Her personal medical history and family history were unremarkable. The lesion was removed by shave excision under local anesthesia. Upon histopathological examination, a polypoid lesion involving a tumoral lesion with central keratinized material was detected. The tumoral lesion was symmetrical and had cup-shaped borders (Figure 2). Keratinocytes in this tumoral lesion had big vesicular nuclei with prominent nucleoli and hyalinized eosinophilic cytoplasms (Figure 3). The tumoral lesion was surrounded by reactive chronic inflammatory cells. There was no tumoral lesion in the surgical margins and consequently, the patient was diagnosed to have a keratoacanthoma located in an acrochordon.
Acrochorda are generally accepted as benign cutaneous lesions. They are excised frequently but infrequently sent for histopathological examination 1 . While the risk of malignant transformation for all skin tags is $0.37 \%$, this risk has been reported to be increased for giant skin tags 2 . Hayes and Berry 3 reported the first unsuspected basal cell carcinoma (BCC) in a skin tag. Three years later, Eads et al. ${ }^{4}$ reported five malignant tumors [four BCCs and one in situ squamous cell carcinoma (SCC)] out of 1135 benign specimens with a skin tag or similar clinical diagnosis submitted for histopathological examination. In the following years, Schwartz et al. ${ }^{1}$ reported a keratoacanthoma-like SCC and Aksoy et al. ${ }^{5}$ reported an additional BCC in acrochorda. These reported cases imply that skin cancer development is rare in acrochorda or inversely low histopathological examination rate is associated with a low detection rate for cutaneous carcinomas present in these benign lesions.

Keratoacanthomas are clinically characterized by sporadic, solitary, fast growing lesions that develop within four to five weeks and regress spontaneously after six months. A reliable clinical marker to discriminate a keratoacanthoma from SCC with a high specificity and sensitivity has not been found

Address for Correspondence/Yazışma Adresi: Berna Aksoy MD, Bahçeşehir University Faculty of Medicine, Department of Dermatology, İstanbul; Medicalpark Hospital, Clinic of Dermatology, Kocaeli, Turkey

Phone: +905326665634 E-mail: bmaksoy@mynet.com Received/Geliş Tarihi: 13.03.2016 Accepted/Kabul Tarihi: 26.07.2016

CCopyright 2017 by Turkish Society of Dermatology and Venereology

Turkderm-Turkish Archives of Dermatology and Venereology published by Galenos Yayınevi. 


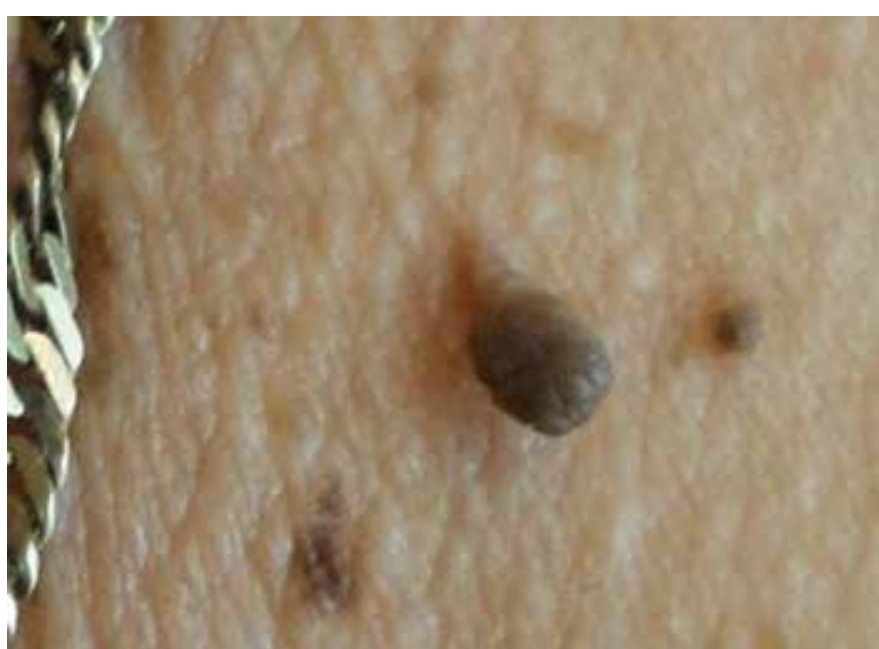

Figure 1. Skin tag located on the left side of the neck

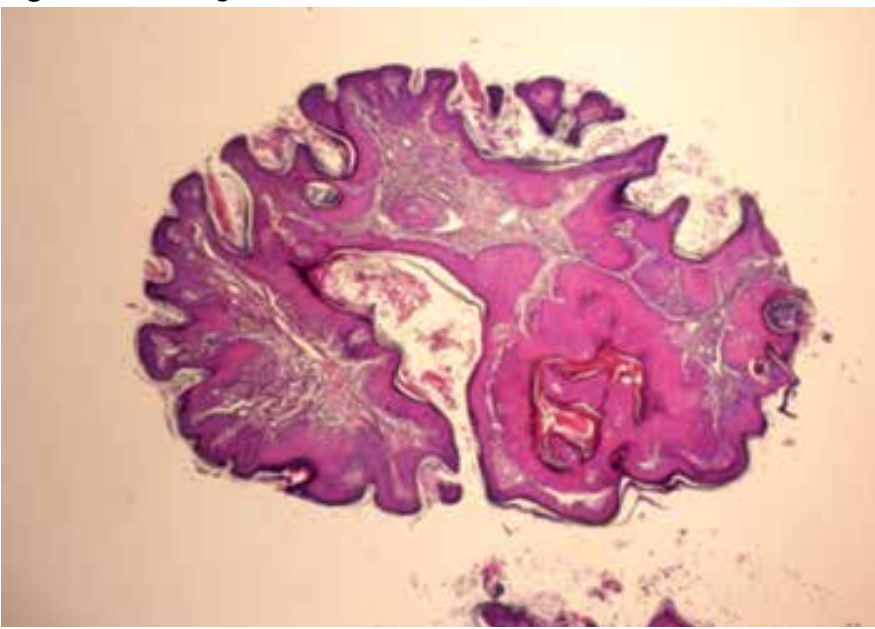

Figure 2. Keratoacanthoma located in a skin tag (hematoxylin\&eosin x20)

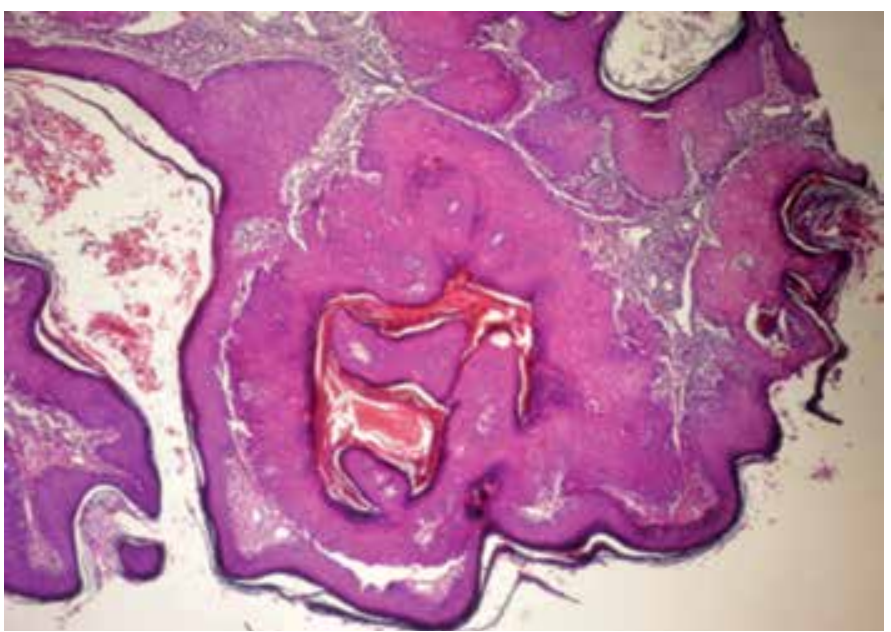

Figure 3. Central keratinous crater in keratoacanthoma (hematoxylin\&eosin x100) until now. There are conflicting ideas in the literature on the nature of keratoacanthomas. Some authors accept keratoacanthomas as a subgroup of SCC or precancerous SCC lesion and some others accept them as a benign lesion different from SCC. Keratoacanthomas show spontaneous regression by apoptotic or immunologic mechanisms. However, it is recommended to actively treat all keratoacanthoma lesions instead of following up due to the risk of serious scar development or potential aggressive behavior6.

Here, we report a histopathologically detected incidental keratoacanthoma within an acrochordon that showed recent fast growth clinically. This case shows us the necessity of sending any resected cutaneous specimen to histopathological examination. Acrochorda are usually excised but generally not examined histopathologically. As a result, there are scarce reports of cutaneous malignancy within acrohorda. Acrohorda may harbour cutaneous malignancy. We obviously cannot detect any malignancy if we do not request histopathological examination. All acrochorda, especially the ones with clinical fast growth as in our case or in patients with a history of sunburn or a family history of skin cancer, should be submitted to histopathological examination following excision.

\section{Ethics}

Informed Consent: Consent form was filled out by all participants. Peer-review: Externally and internally peer-reviewed.

\section{Authorship Contributions}

Surgical and Medical Practices: Hasan Mete Aksoy, Berna Aksoy, Concept: Berna Aksoy, Hasan Mete Aksoy, Design: Berna Aksoy, Data Collection or Processing: Berna Aksoy, Hasan Mete Aksoy, Onat Akın, Analysis or Interpretation: Onat Akın, Berna Aksoy, Literature Search: Berna Aksoy, Writing: Berna Aksoy, Hasan Mete Aksoy, Onat Akın.

Conflict of Interest: No conflict of interest was declared by the authors. Financial Disclosure: The authors declared that this study received no financial support.

\section{References}

1. Schwartz RA, Tarlow MM, Lambert WC: Keratoacanthoma-like squamous cell carcinoma within the fibroepithelial polyp. Dermatol Surg 2004;30:34950.

2. Aksoy B, Aksoy HM, Civaş E, Üstün H: Giant skin tags located in the lower half of the body: Report of two cases. Turkiye Klinikleri J Med Sci 2009;29:1770-2

3. Hayes AG, Berry AD: Basal cell carcinoma arising in a fibroepithelial polyp. $J$ Am Acad Dermatol 1993;28:493-5.

4. Eads TJ, Chuang T-Y, Fabre VC, et al: The utility of submitting fibroepithelial polyps for histopathological examination. Arch Dermatol 1996;132:145962.

5. Aksoy B, Aksoy HM, Üstün $\mathrm{H}$, et al: Basal cell carcinoma in a skin tag. Eur J Dermatol 2008;18:605-6.

6. Ko CJ: Keratoacanthoma: facts and controversies. Clin Dermato 2010;28:254-61. 